\title{
High WDR34 mRNA expression as a potential prognostic biomarker in patients with breast cancer as determined by integrated bioinformatics analysis
}

\author{
DAO-JUN HU ${ }^{1 *}$, WEN-JIE SHI ${ }^{2 *}$, MIAO YU ${ }^{1}$ and LI ZHANG ${ }^{1}$ \\ ${ }^{1}$ Department of Clinical Laboratory, Xin Hua Hospital Affiliated to Shanghai Jiao Tong University School of \\ Medicine (Chongming Branch), Shanghai 202150; ${ }^{2}$ Department of Breast Surgery, Affiliated \\ Hospital of Guilin Medical University, Guilin, Guangxi 541000, P.R. China
}

Received September 23, 2018; Accepted June 6, 2019

DOI: $10.3892 / \mathrm{ol} .2019 .10634$

\begin{abstract}
The WD-repeat domain (WDR) family is distributed in the majority of eukaryotes and has several unique biological functions. It serves important roles in signal transduction, cytoskeleton assembly, protein transport, RNA processing, chromatin modification and transcription mechanisms. WD repeat domain 34 (WDR34) has been recently identified as a member of the WDR family. Overexpression of WDR34 was accompanied by the presence of multiple centrioles in the cell, suggesting that it was associated with tumor occurrence. However, its association with breast cancer was unclear. To the best of our knowledge, it has not yet been confirmed whether WDR34 gene expression is associated with breast cancer. Therefore, the current study attempted to clarify this by performing a comprehensive study using multiple datasets in the Oncomine, Breast Cancer Gene-Expression Miner and Kaplan-Meier Plotter databases. The analysis indicated that the mRNA expression levels of WDR34 were increased in breast cancer tissues compared with normal tissues. Consistent with this result, the Broad-Novartis Cancer Cell Line Encyclopedia revealed that WDR34 mRNA expression levels were upregulated in breast cancer cell lines compared with other cancer cells. It was noted that high WDR34 mRNA expression was associated with forkhead box M1 and PTTG1 regulator of sister chromatid separation, securing in co-expression analysis. Expression profile characteristics of WDR34 mRNA were identified in different molecular subtypes of breast
\end{abstract}

Correspondence to: Professor Li Zhang, Department of Clinical Laboratory, Xin Hua Hospital Affiliated to Shanghai Jiao Tong University School of Medicine (Chongming Branch), 25 Nanmen Road, Chongming, Shanghai 202150, P.R. China

E-mail: labzl@hotmail.com

${ }^{*}$ Contributed equally

Key words: WD repeat domain 34, breast cancer, Oncomine, Kaplan-Meier plotter cancer. Furthermore, survival analysis revealed that increased expression levels of WDR34 mRNA were associated with poor overall survival in patients with breast cancer, particularly in luminal B, lymph node status-positive and estrogen receptor (ER)-negative subgroups. Additionally, Kaplan-Meier curves revealed that high WDR34 mRNA expression was associated with shorter relapse-free survival in patients with breast cancer, particularly in ER-positive, human epidermal growth factor receptor 2-negative and progesterone receptor-positive subgroups. These results suggested that WDR34 may be used as a prognosis predictor in breast cancer and may provide a novel target for the diagnosis and treatment of breast cancer.

\section{Introduction}

Breast cancer is the most widespread cancer and the second-leading cause of cancer-associated mortality among females worldwide (data from Cancer Statistics 2018), despite the availability of effective chemotherapy agents $(1,2)$. Cytotoxic and molecular targeted anti-cancer therapies remain the major treatment options for breast cancer (3). The greatest challenges in the management of patients with breast cancer include the determination of prognosis and the identification of appropriate adjuvant systemic therapies (4). Therefore, there is a requirement for effective prognostic biomarkers for patients with refractory breast cancer.

WD-repeat domain (WDR)-containing proteins are characterized by a common sequence repeat of tryptophan and aspartic acid pairs are generally found at the end of their 40-residue-long amino acid sequences (5). WDRs, including DR13, DCAF4L2, WD48, BOP1 and CIRH1A, serve as platforms for the assembly of protein complexes or mediators of transient interplay between other proteins (6).

WD domain repeat 34 (WDR34), a member of the WDR superfamily, encodes a highly conserved protein consisting of 536 amino acids, with human and mouse WDR34 sharing $83 \%$ homology. WDR34 acts as a mitogen-activated protein kinase kinase kinase 7-associated inhibitor of the interleukin-1 receptor/Toll-like receptor (TLR)3/TLR4-induced nuclear factor- $\kappa \mathrm{B}$ activation pathway $(7,8)$. Studies have revealed that WDR34 mutations may result in short-rib polydactyly syndrome 
type III or severe asphyxiating thoracic dysplasia $(8,9)$. A study by Wu et al (10) indicated that WDR34-mutant mice succumb in mid-gestation and exhibit open brain and polydactyly phenotypes. WDR34 downregulation was identified in oral squamous cell carcinoma tissues compared with normal control tissues (11). Research from cDNA microarrays demonstrated that WDR34 had a 6.8-fold difference in expression between cases with and without recurrence in patients with bladder cancer (12). Although numerous studies have suggested that WDR34 expression is associated with the progression of cancer, the role of WDR34 expression in the tumorigenesis and prognosis of breast cancer remains unknown.

In the present study, a bioinformatics analysis based on a number of public clinical databases was performed in order to investigate WDR34 expression in breast cancer and normal tissues. The aim of the present study was to identify a possible biomarker suitable for the prognostic prediction of patients with breast cancer.

\section{Materials and methods}

Oncomine analysis. The WDR34 mRNA expression level was analyzed in breast cancer and matched normal tissues based on the The Oncomine Platform (www.oncomine. org), which consists of 715 datasets and 86,733 samples. The analysis was conducted using the following filters: i) Gene, WDR34; ii) differential analysis, cancer vs. normal analysis; iii) cancer type, breast cancer; and iv) data type, mRNA. In the current study, all statistical methods and statistical values were obtained directly from the corresponding database. The threshold for statistical significance was set as $\mathrm{P}<0.01$; fold change $>2$; and gene rank, top $10 \%$.

The present study involved a meta-analysis using a random permutation method and further illustrated WDR34 gene expression in different breast cancer datasets from Oncomine (13).

Breast Cancer Gene-Expression Miner (bc-GenExMiner). In the present study, the expression of WDR34 mRNA in different subtypes of breast cancer and the correlation between genes or identified clusters of correlated co-expressed genes were analyzed using bc-GenExMiner (version 4.1; bcgenex. centregauducheau.fr). bc-GenExMiner includes 36 annotated genomic datasets and 5,861 patients with breast cancer $(14,15)$.

Cancer Cell Line Encyclopedia (CCLE) analysis. WDR34 mRNA expression in breast cancer cell lines was analyzed using the CCLE database (portals.broadinstitute.org/ccle/home), which provides public access to genomic data, analysis and visualization for 947 human cancer cell lines.

Kaplan-Meier survival curve analysis. The prognostic value of WDR34 mRNA expression in breast cancer was assessed according to overall survival (OS) and relapse-free survival (RFS) using Kaplan-Meier plotter (kmplot.com/analysis) up to June 302018 (16). Log-rank P-values and hazard ratios (HRs) with $95 \%$ confidence intervals were determined on the webpage.

The Cancer Genome Atlas (TCGA) data and cBioPortal. The invasive breast carcinoma dataset (TCGA, Provisional), consisting of 1,105 samples with pathology reports, was selected for further analysis of WDR34 expression using cBioPortal (www.cbioportal.org) $(17,18)$. The selected genomic profiles included putative copy-number alterations from GISTIC_2.0 (http://portals.broadinstitute.org/cgi-bin/cancer/ publications/pub_paper.cgi?mode=view\&paper_id=216\&p=t), and the selected patient/case sets included tumor samples with RNA data (RNA Seq V2). Disease-free survival (DFS) or OS results were derived from cBioPortal using the OS Kaplan-Meier estimate. The proportion and distribution of samples with WDR34 alterations were presented in the Oncoprint (http://www.canvasxpress.org/html/oncoprint-2. html), which is a visual image used to show changes in different genomes, including mutations, copy number changes and mRNA expression. All statistical methods and statistical results in this study came from the corresponding online database.

\section{Results}

mRNA expression profiles of WDR34 in different tumor types. A total of 304 unique analyses were gathered from different types of cancer in the Oncomine database. The results of 20 analyses demonstrated statistical significance; 19 analyses consisted of high expression and one analysis consisted of reduced expression. Notably, the mRNA expression of WDR34 in breast cancer was the highest among different cancer types (Fig. 1A)

Using data from a previous study by Curtis et al (19), it was demonstrated that WDR34 mRNA expression was increased 2.034- and 2.103-fold in breast cancer tissues compared with normal tissues (Fig. 1C and D). A consistent result was identified in another dataset derived from TCGA, consisting of 593 breast cancer samples; WDR34 mRNA expression was increased 2.199-fold in breast cancer tissues when compared with normal tissues (Fig. 1E). To demonstrate the reliability of the study, a meta-analysis of 27 studies from 10 datasets obtained from the Oncomine database was performed. It was revealed that the expression of WDR34 mRNA in breast cancer tissues was significantly higher compared with that in normal controls ( $\mathrm{P}=0.002$; Fig. 1B).

Furthermore, upregulation of WDR34 mRNA was identified in breast cancer cell lines using CCLE analysis. This result was consistent with that obtained from the breast cancer tissues (Fig. 2).

WDR34 mRNA expression is associated with molecular subtypes of breast cancer. In the BC-GenExMiner database, the expression level of WDR34mRNA was analyzed in different types of breast cancer tissues. The expression level of WDR34 mRNA in patients with human epidermal growth factor receptor 2 (HER2)-positive breast cancer was increased compared with patients with HER2-negative breast cancer $(\mathrm{P}=0.0242$; Fig. $3 \mathrm{~A})$. However, there were no statistically significant differences observed regarding the WDR34 mRNA expression level in patients with estrogen receptor (ER)-positive or ER-negative breast cancer (Fig. 3B). Similar results were obtained for patients with progesterone receptor (PR)-positive and PR-negative breast cancer (Fig. 3C). 

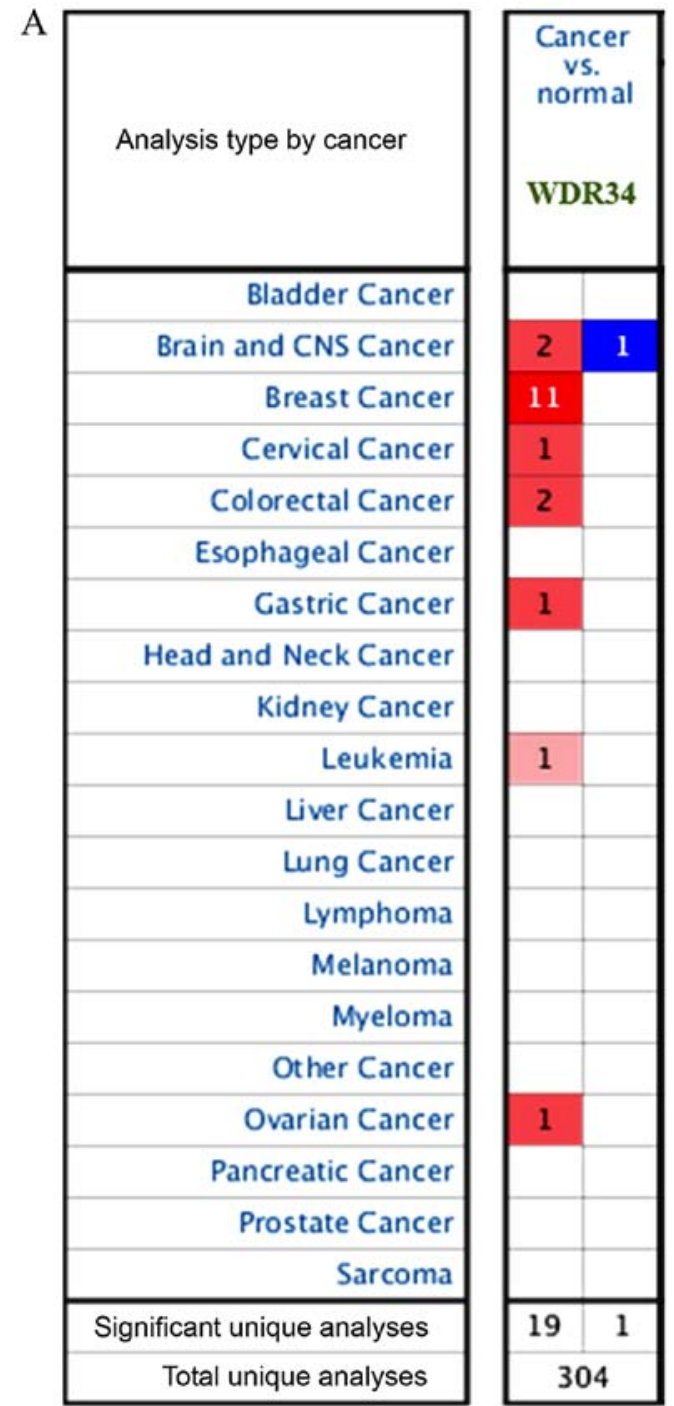

B

Comparison of WDR34 accross 27 analyses

Over-expression
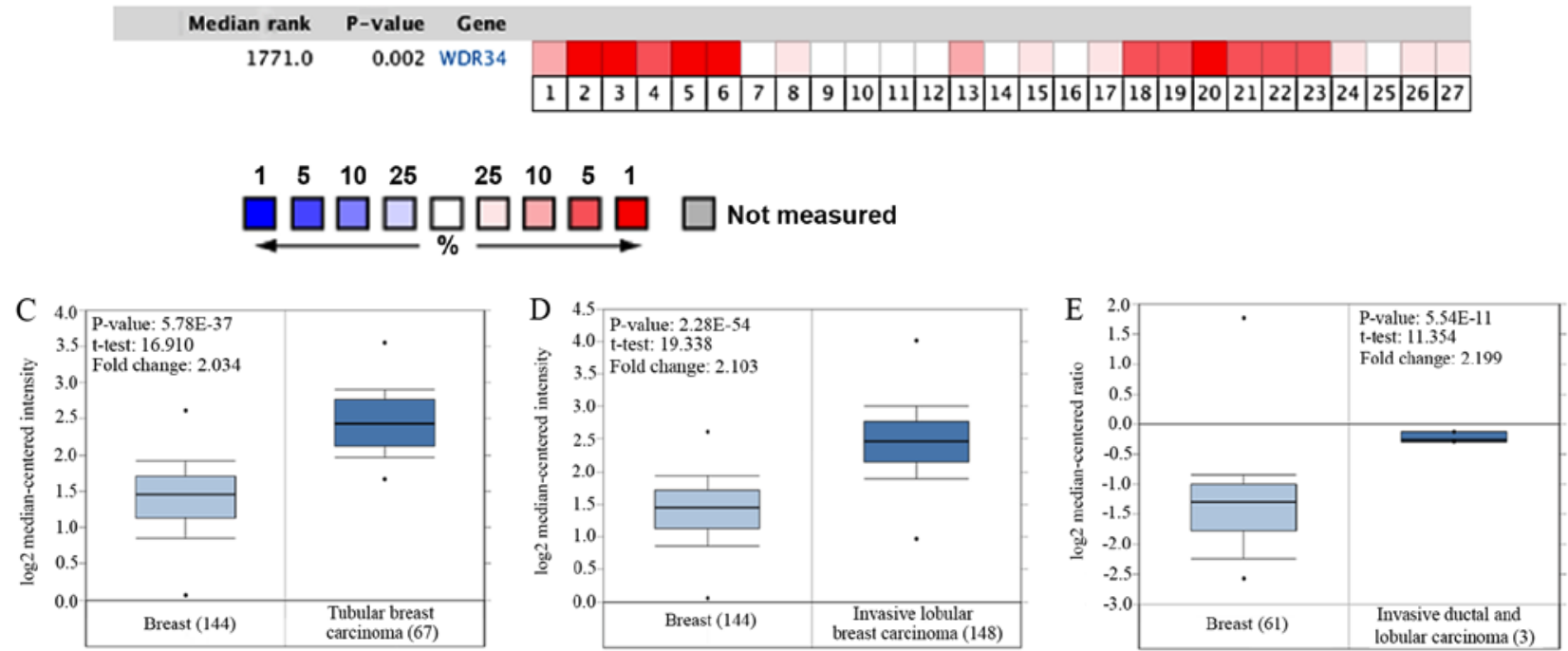

Figure 1. mRNA expression patterns of WDR34 in breast cancer tissues compared with normal tissues. (A) Expression pattern analysis of WDR34 mRNA in different cancer tissues performed in the Oncomine database. The number of datasets with statistically significant $(\mathrm{P}<0.01)$ WDR34 mRNA upregulation (red) or reduced expression (blue) in the different types of cancer vs. corresponding normal tissue are presented. The gene rank was analyzed according to the percentile of the target gene in the top of all genes measured in each research. Cell color is determined by the best gene rank percentile for the analyses within the cell. The P-value threshold was 0.01. (B) Expression of WDR34 in patients with breast cancer in studies identified in the Oncomine database. 1-27 represent the 27 studies on the expression of WDR34 in patients with breast cancer. Red indicates higher WDR34 expression and blue indicates lower WDR34 expression. (C-E) Respective expression levels of WDR34 mRNA in the Breast Statistics study or Curtis Breast Statistics (breast cancer tissues vs. corresponding normal tissues). The P-value threshold was $<0.01$ and threshold for fold-change was 2.0. WDR34, WD domain repeat 34. 


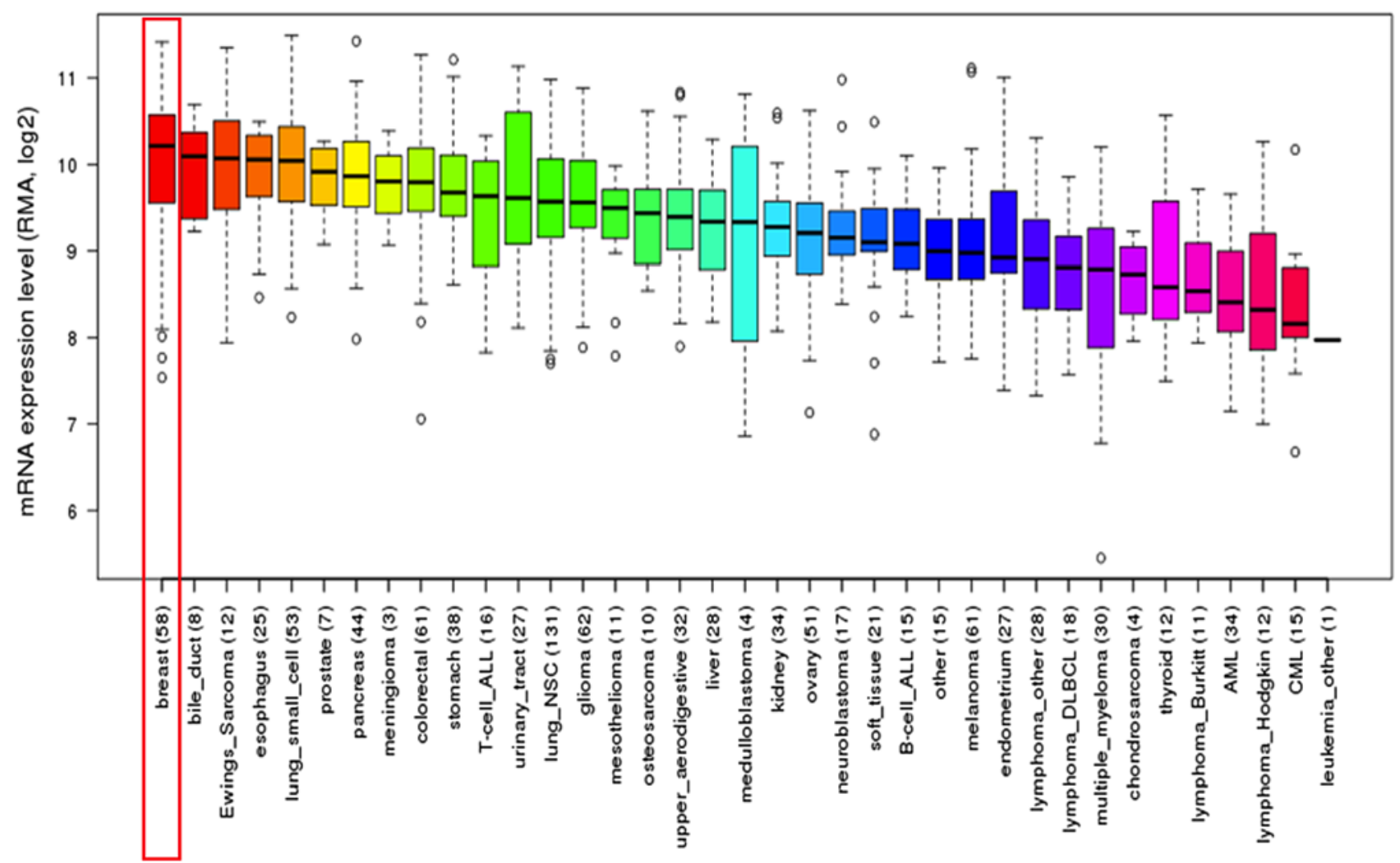

Figure 2. WD domain repeat 34 is expressed prominently in breast cancer cell lines according to the Cancer Cell Line Encyclopedia analysis. The numbers in brackets following the type of cancer on the $\mathrm{x}$-axis represent the number of cell lines.

Breast cancer subtypes were determined according to SCM1 classification using the bc-GenExMiner. Notably, WDR34 mRNA expression in the HER2 subtype was significantly increased compared with the luminal A and luminal B subtypes $(\mathrm{P}<0.0001$; Dunnett-Tukey-Kramer's test; Fig. 3D). Furthermore, WDR34 mRNA expression was not significantly different between patients with basal-like and non-basal-like breast cancer ( $\mathrm{P}=0.8841$; Fig. 3E). Similarly, WDR34 mRNA expression was not significantly different between patients with triple negative breast cancer (TNBC) and non-TNBC patients ( $\mathrm{P}=0.1754$; Fig. 3F).

Regarding the Scarff Bloom and Richardson (SBR) grade status, higher WDR34 mRNA expression was significantly associated with a more advanced SBR grade $(\mathrm{P}<0.0001$; Dunnett-Tukey-Kramer's test; Fig. 3G). Regarding the Nottingham Prognostic Index (NPI) status, a higher NPI level was significantly associated with increased WDR34 mRNA expression $(\mathrm{P}<0.0001$; Dunnett-Tukey-Kramer's test; Fig. 3H). When age was taken into account, it was identified that WDR34 mRNA expression was not significantly elevated with increasing age ( $\mathrm{P}=0.5179$; Fig. 3I).

High expression of WDR34 mRNA is correlated with high expression of forkhead box M1 (FOXM1) and PTTG1 regulator of sister chromatid separation securin (PTTG1). It was demonstrated that WDR34 mRNA expression was upregulated in breast cancer. Therefore, an in-depth exploration on whether WDR34 was associated with other potential gene biomarkers was performed. In the bc-GenExMiner, mRNA correlation analysis indicated that high WDR34 mRNA expression was positively correlated with the expression of FOXM1 ( $\mathrm{r}=0.35$; P<0.0001; Fig. 4A) and PTTG1 $(r=0.29 ; \mathrm{P}<0.0001 ;$ Fig. 4B). A correlation map for all patients was produced for WDR34, FOXM1 and PTTG1 (Fig. 4C).

Increased WDR34 mRNA expression indicates poor OS in patients with breast cancer, particularly in luminal $B$, lymph node status-positive and ER-negative subgroups. The potential prognostic value of WDR34 mRNA expression in patients with breast cancer was further assessed. The current study indicated that high WDR34 mRNA expression was associated with shorter OS in patients with breast cancer $(\mathrm{HR}=1.48$; $\mathrm{P}=0.015$; Fig. 5A). Sub-analysis indicated that high WDR34 mRNA expression was associated with shorter OS in luminal $\mathrm{B}(\mathrm{HR}=2.50 ; \mathrm{P}=0.012$; Fig. 5C), but not luminal A (HR=0.85; $\mathrm{P}=0.53$; Fig. 5B). Furthermore, high WDR34 mRNA expression was correlated with shorter OS in patients with ER-negative breast cancer (HR=2.34; $\mathrm{P}=0.021$; Fig. 5E), but not in those with ER-positive breast cancer (HR=1.27; $\mathrm{P}=0.54$; Fig. 5D). In patients with breast cancer with a positive lymph node status, a significant correlation was identified between high WDR34 mRNA expression and OS (HR=2.06; $\mathrm{P}=0.0096$; Fig. 5H); however, a correlation was not indicated in patients with breast cancer with a negative lymph node status $(\mathrm{HR}=0.86 ; \mathrm{P}=0.75$; Fig. 5I). Significant differences were not observed in breast cancer subtypes including HER2-positive ( $\mathrm{HR}=1.52 ; \mathrm{P}=0.49$; Fig. 5F), HER2-negative $(\mathrm{HR}=0.56 ; \mathrm{P}=0.30$; Fig. 5G) and basal subgroups ( $\mathrm{HR}=1.10 ; \mathrm{P}=0.76$; data not shown).

Elevated WDR34 mRNA expression is correlated with shorter RFS in patients with breast cancer, particularly in ER-positive, 
A
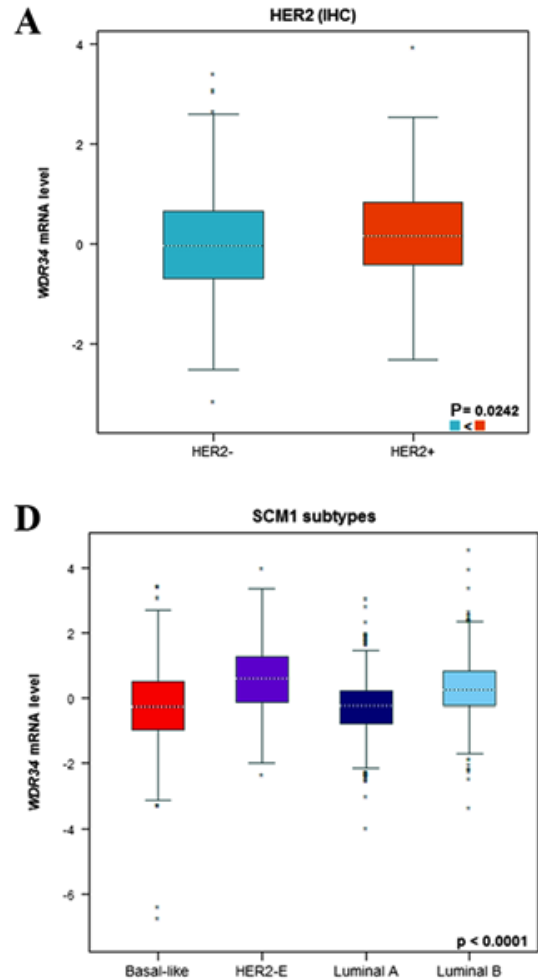

G

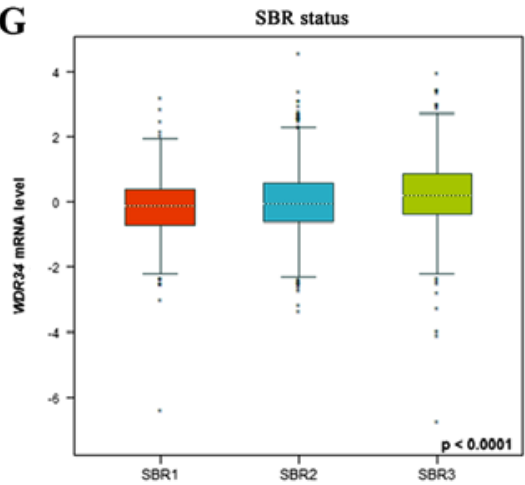

B

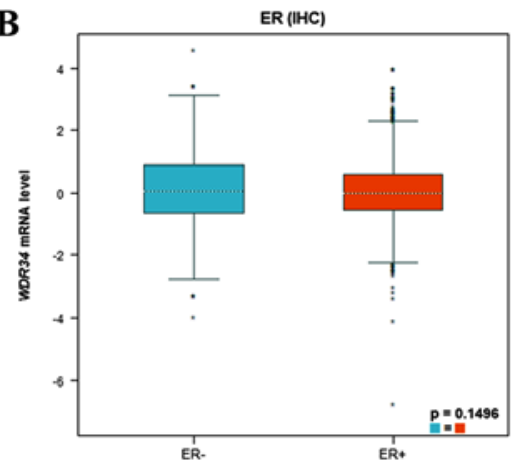

E

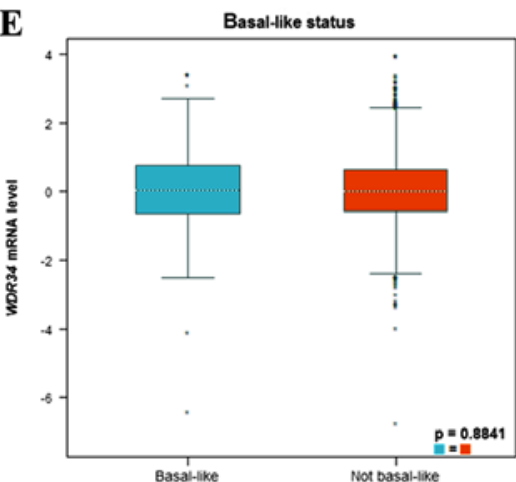

H

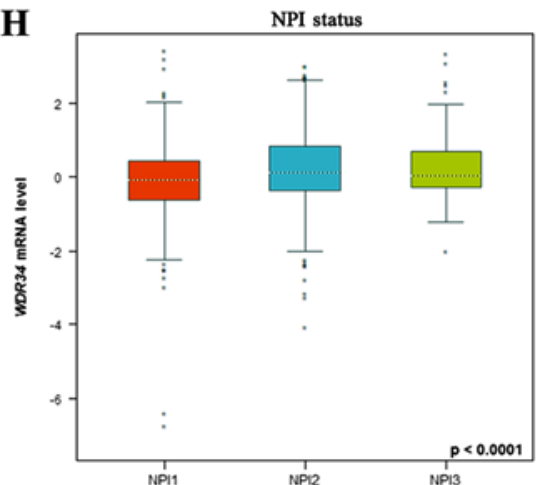

C

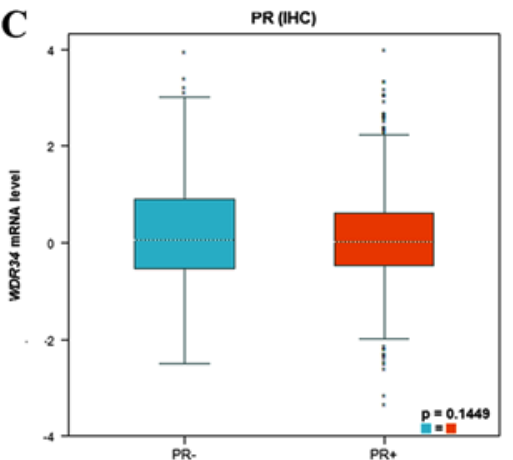

F

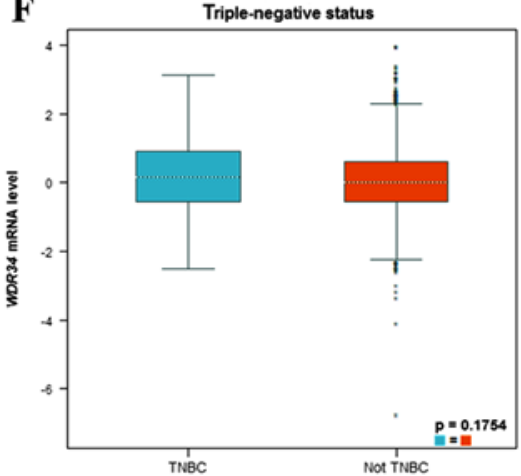

I

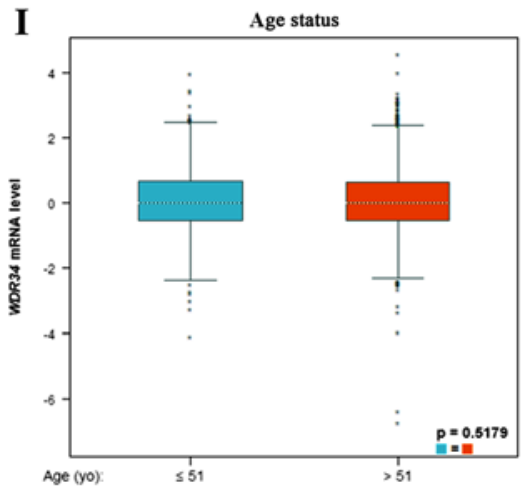

Figure 3. WDR34 mRNA expression in molecular subtypes of breast cancer. The data were generated from the Breast Cancer Gene Expression Miner database. Overall significant differences between groups were assessed by Welch's test to generate a P-value. Dunnett-Tukey-Kramer's tests were used for pairwise comparisons when an overall significant difference existed $(\mathrm{P}<0.05)$. (A) mRNA expression of WDR34 in patients with HER2-positive and HER2-negative breast cancer. (B) mRNA expression of WDR34 in patients with ER-positive and ER-negative breast cancer. (C) mRNA expression of WDR34 in patients with PR-positive and PR-negative breast cancer. (D) mRNA expression of WDR34 in different SCM1 subtypes of breast cancer patients. (E) The mRNA expression of WDR34 between basal-like and non-basal-like breast cancer. (F) mRNA expression of WDR34 in patients with TNBC and non-TNBC patients. (G) The mRNA expression of WDR34 according to SBR status. (H) mRNA expression of WDR34 according to NPI status. (I) mRNA expression of WDR34 in different age groups. WDR34, WD repeat domain 34; HER2, human epidermal growth factor receptor 2; ER, estrogen receptor; PR, progesterone receptor; SCM, subcutaneous mastectomy; TNBC, triple-negative breast cancer; SBR, Scarff Bloom and Richardson; NPI, Nottingham Prognostic Index; IHC, immunohistochemistry.

HER2-negative and PR-positive subgroups. High WDR34 mRNA expression was significantly associated with shorter RFS in breast cancer patients (HR=1.59; $\mathrm{P}=5.7 \times 10^{-09}$; Fig. $6 \mathrm{~A}$ ). Sub-analysis on different subtypes of breast cancer was conducted, which indicated that high WDR34 mRNA expression was correlated with shorter RFS in patients with ER-positive $(\mathrm{HR}=1.40 ; \mathrm{P}=0.024$; Fig. 6D), but not in ER-negative breast cancer $(\mathrm{HR}=1.23 ; \mathrm{P}=0.22$; Fig. $6 \mathrm{E})$. Moreover, high WDR34 mRNA expression was correlated with shorter RFS in patients with PR-positive (HR=1.62; $\mathrm{P}=0.013$; Fig. 6F), HER2-negative $(\mathrm{HR}=1.40 ; \mathrm{P}=0.027$; Fig. $6 \mathrm{I})$ and lymph node status-positive (HR=1.61; $\mathrm{P}=2 \times 10^{-04} ;$ Fig. $6 \mathrm{~J}$ ) breast cancer subtypes, but not in PR-negative (HR=1.29; $\mathrm{P}=0.16$; Fig. 6G), HER2-positive ( $\mathrm{HR}=0.94 ; \mathrm{P}=0.83$; Fig. $6 \mathrm{H})$, lymph node status-negative ( $\mathrm{HR}=1.05 ; \mathrm{P}=0.81$; Fig. $6 \mathrm{~K})$, luminal $\mathrm{A}(\mathrm{HR}=1.25 ; \mathrm{P}=0.071$; Fig. 6B), luminal $\mathrm{B}(\mathrm{HR}=1.32 ; \mathrm{P}=0.074$; Fig. $6 \mathrm{C}$ ) or basal $(\mathrm{HR}=1.26 ; \mathrm{P}=0.16$; Fig. $6 \mathrm{~L})$ breast cancer subtypes.

WDR34 mRNA mutations do not affect OS or DFS in patients with breast cancer. A total of 66/1,093 (6\%) sequenced patients with invasive breast carcinoma exhibited alterations of WDR34. The Kaplan-Meier plot and log-rank test identified that the alterations of WDR34 had no significant influence on the OS or DFS of patients with breast cancer (Fig. 7). 

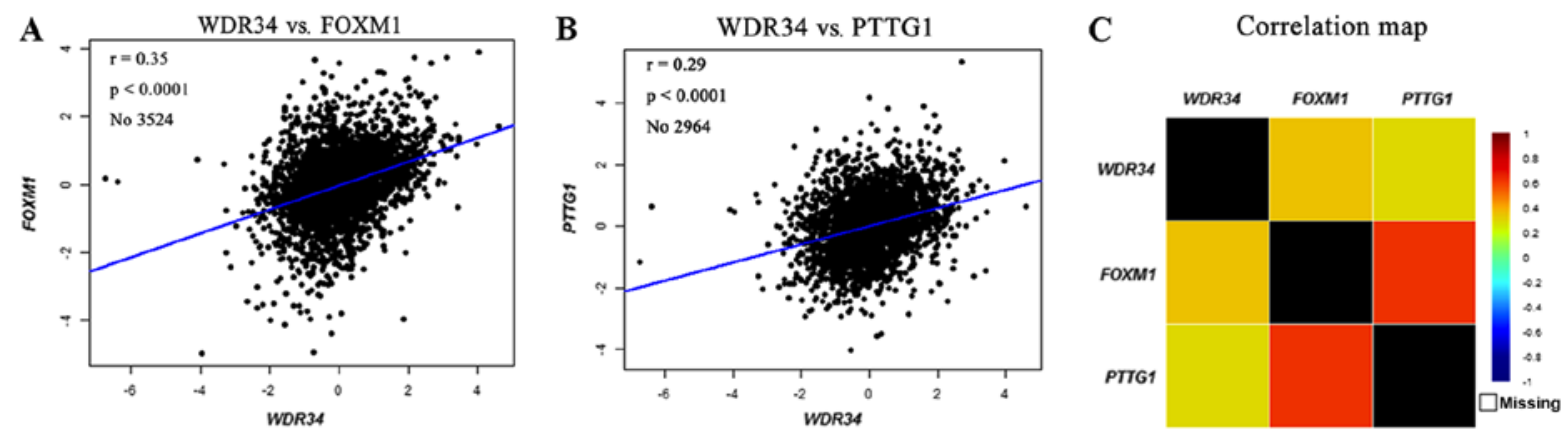

Figure 4. High WDR34 mRNA expression is positively correlated with FOXM1 and PTTG1. In the Breast Cancer Gene Expression Miner database, Pearson's pairwise correlation analysis between WDR34 and FOXM1 or between WDR34 and PTTG1 was performed for all patients. (A) Gene correlation targeted analysis between WDR34 and FOXM1. (B) Gene correlation targeted analysis between WDR34 and PTTG1. (C) Correlation map for all patients among FOXM1, PTTG1 and WDR34. WDR34, WD domain repeat 34; FOXM1, forkhead box M1; PTTG1, PTTG1 regulator of sister chromatid separation securin.

A

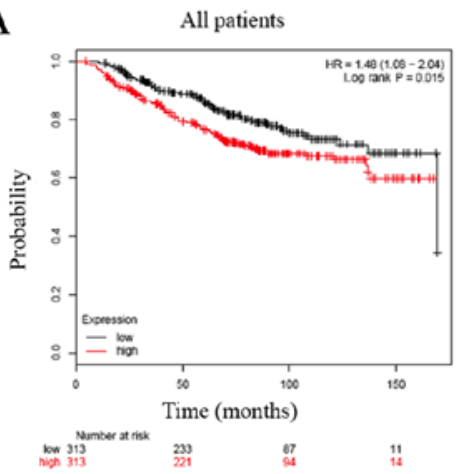

D

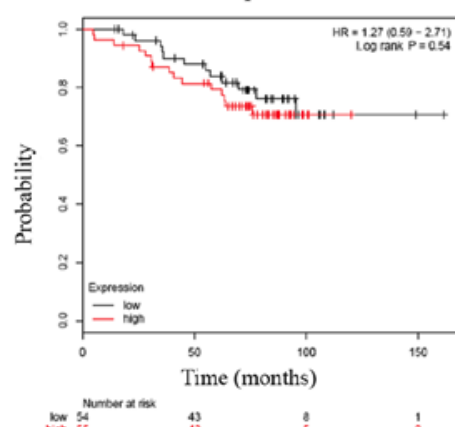

G

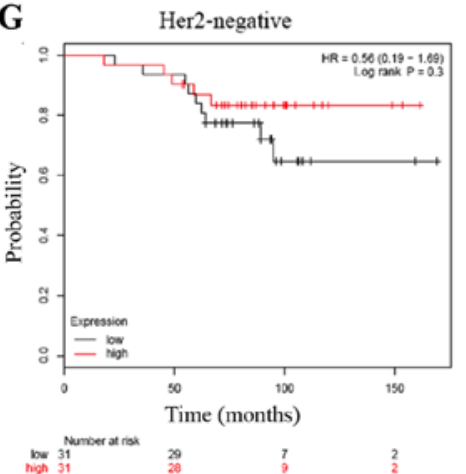

B

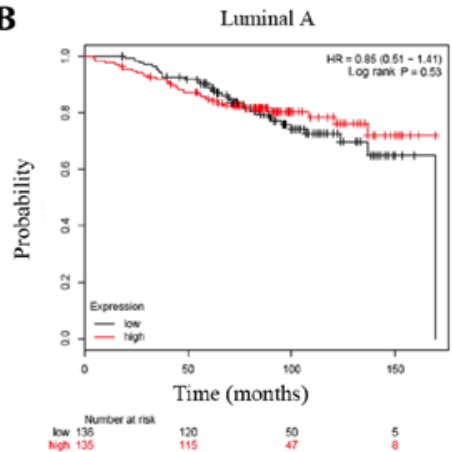

$\mathbf{E}$

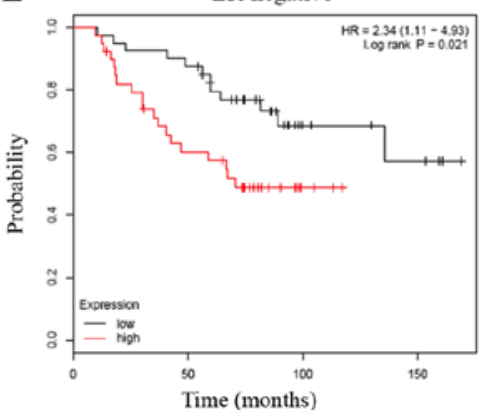

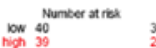

H

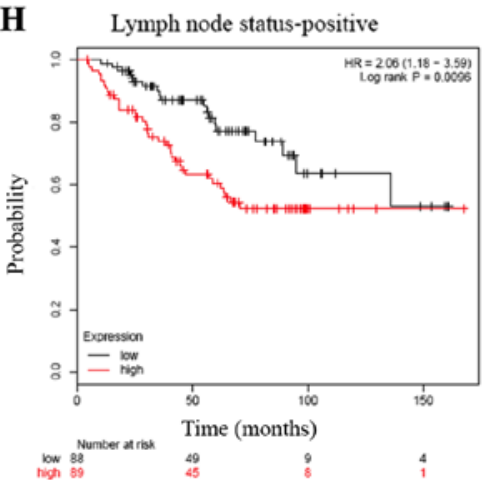

C

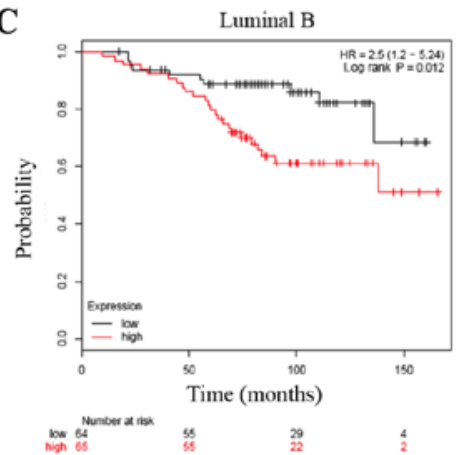

F

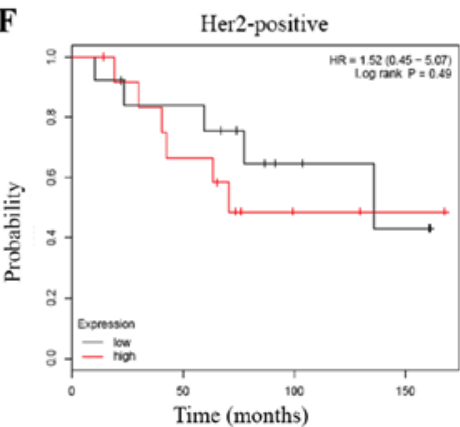

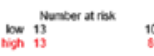

I Lymph node status-negative

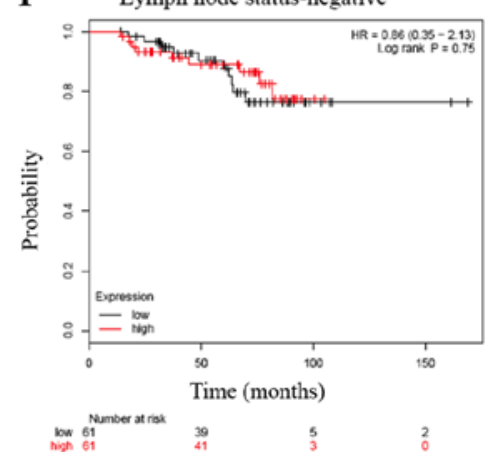

Figure 5. Prognostic values of WDR34 mRNA expression in patients with breast cancer. The OS was determined using the Kaplan-Meier Plotter. (A) High WDR34 mRNA expression was associated with shorter OS in patients with breast cancer. High WDR34 mRNA expression was not associated with shorter OS in (B) patients with luminal A breast cancer but resulted in shorter OS in (C) patients with luminal B breast cancer. High WDR34 mRNA expression was not associated with shorter OS in (D) patients with ER-positive breast cancer, but was associated with shorter OS in (E) patients with ER-negative breast cancer. WDR34 mRNA expression was not associated with shorter OS in patients with (F) HER2-positive or (G) HER2-negative breast cancer. High WDR34 mRNA expression was associated with shorter OS in (H) patients with lymph node status-positive breast cancer, but not (I) patients with lymph node status-negative breast cancer. WDR34, WD domain repeat 34; OS, overall survival; ER, estrogen receptor; HER2, human epidermal growth factor receptor 2. 
A

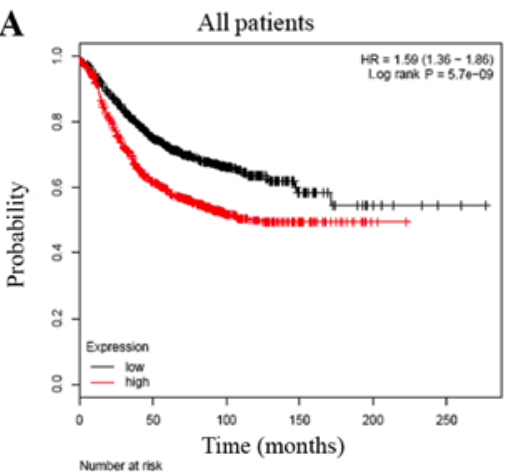

D

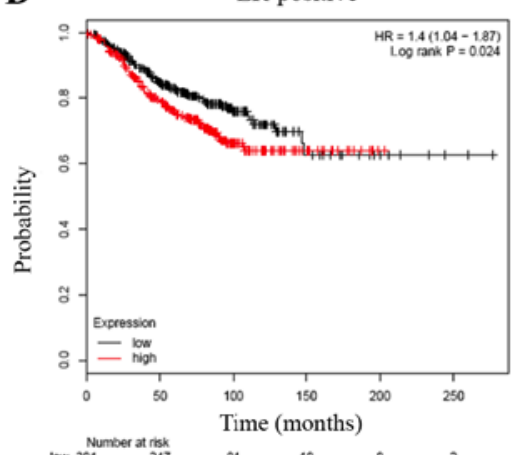

G

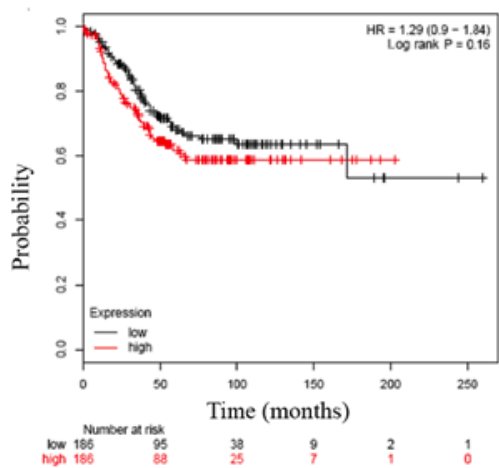

$\mathbf{J}$

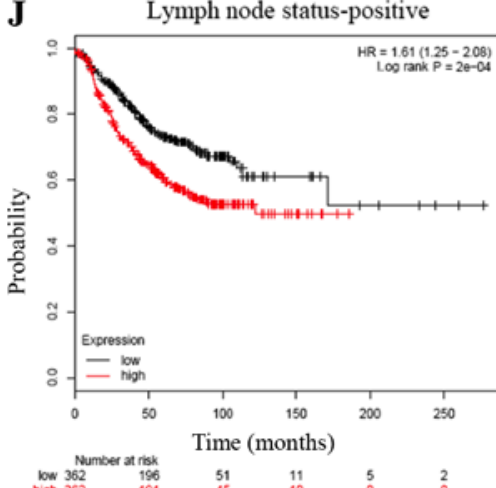

B

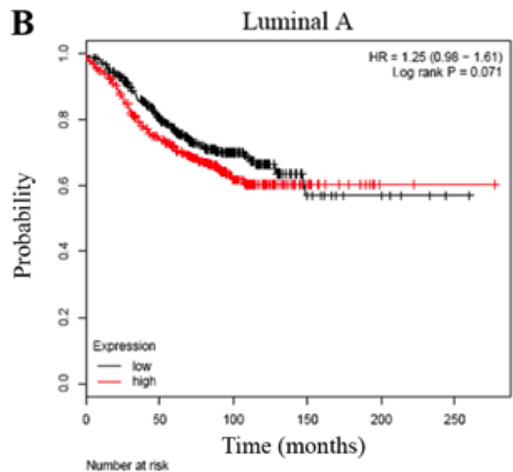

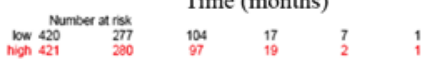

E

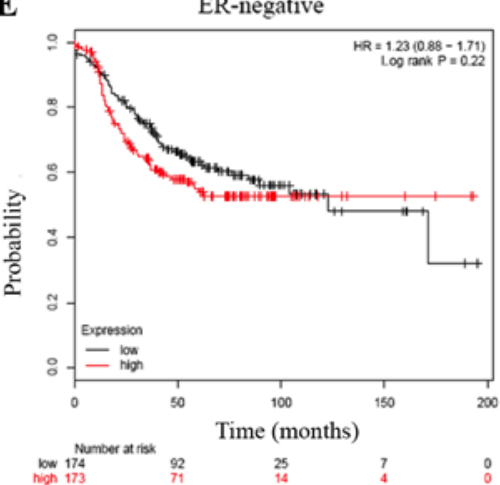

H

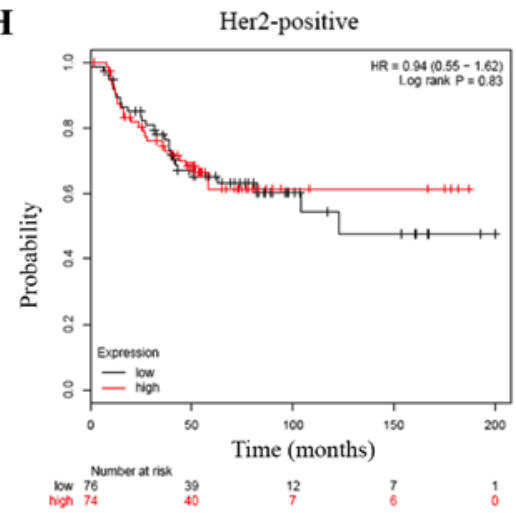

$\mathbf{K}$

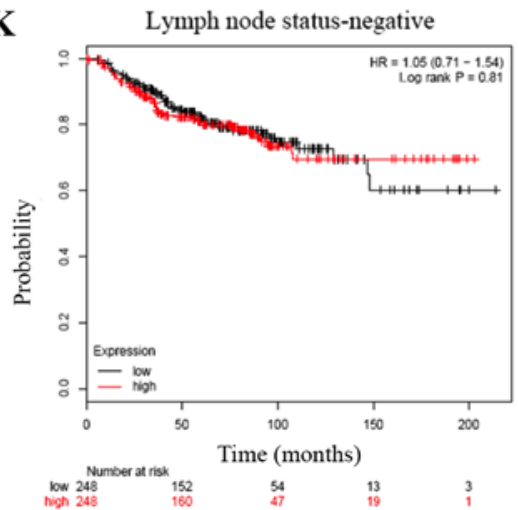

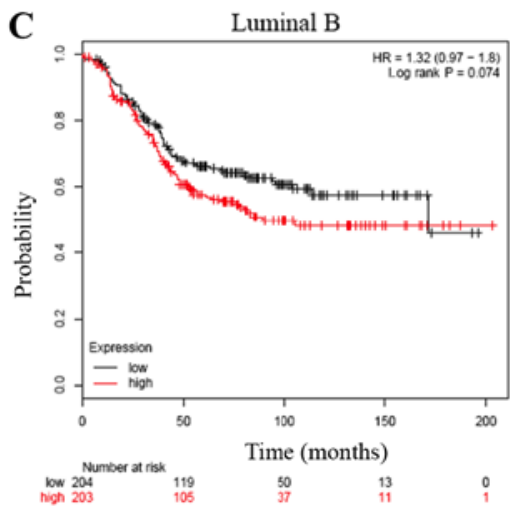

F

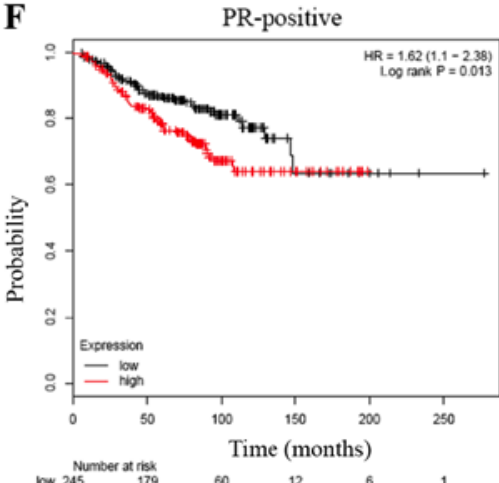

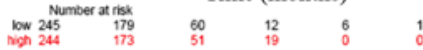

I Her2-negative

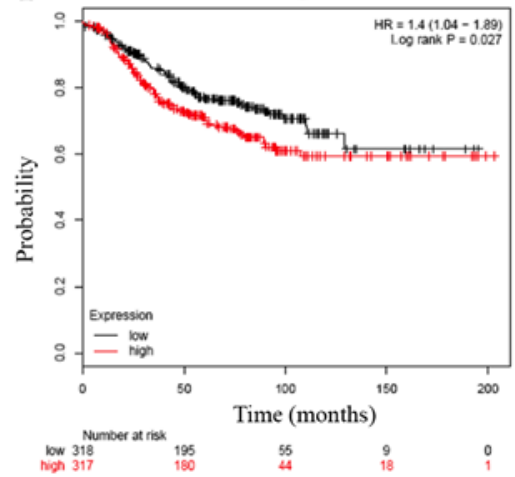

L

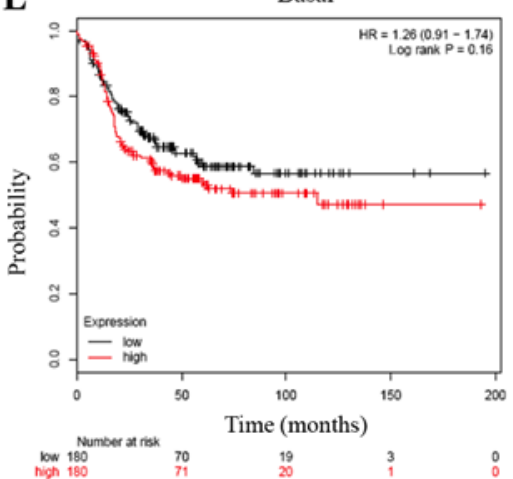

Figure 6. Prognostic value of WDR34 mRNA expression in patients with breast cancer. The RFS was determined using the Kaplan-Meier Plotter. (A) High WDR34 mRNA expression was significantly associated with shorter RFS in all patients with breast cancer. High WDR34 mRNA expression was not associated with shorter RFS in patients with (B) luminal A or (C) luminal B breast cancer. High WDR34 mRNA expression was associated with shorter RFS in (D) patients with ER-positive breast cancer, but not (E) patients with ER-negative breast cancer. High WDR34 mRNA expression was associated with shorter RFS in (F) patients with PR-positive breast cancer, but not (G) patients with PR-negative breast cancer. WDR34 mRNA expression was not associated with shorter RFS in (H) patients with HER2-positive breast cancer, but was associated with shorter RFS in (I) patients with HER2-negative breast cancer. High WDR34 mRNA expression was associated with shorter RFS in (J) patients with lymph node status-positive breast cancer, but not (K) patients with lymph node status-negative breast cancer. (L) High WDR34 mRNA expression was not associated with shorter RFS in patients with basal-like breast cancer. WDR34, WD domain repeat 34; RFS, relapse-free survival; ER, estrogen receptor; PR, progesterone receptor; HER2, human epidermal growth factor receptor 2. 

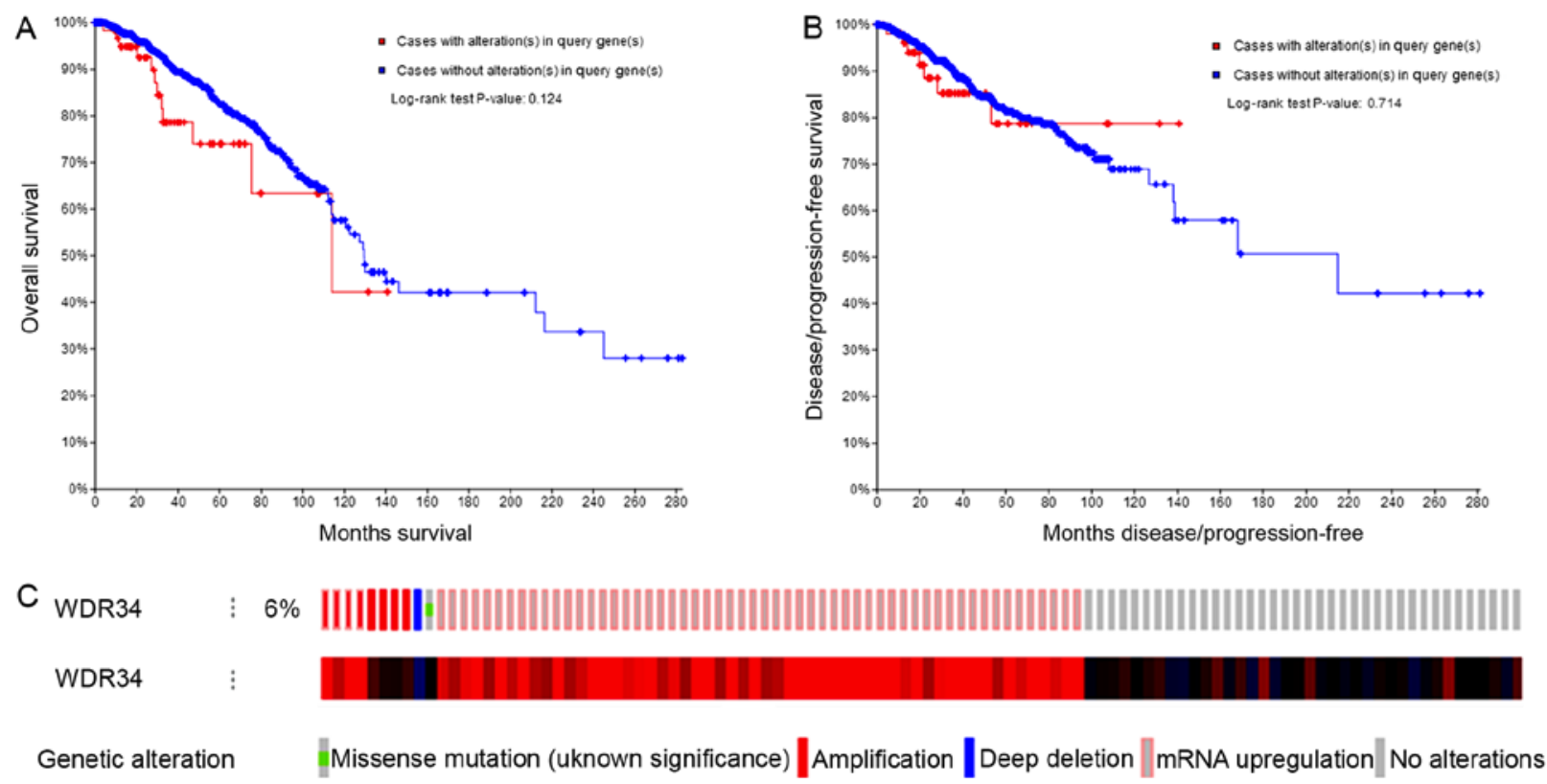

Figure 7. WDR34 mRNA expression and mutation analysis in invasive breast carcinoma. (A) Overall survival analysis was performed in cases with or without WDR34 alterations. (B) Disease-free survival was performed in cases with or without WDR34 alterations. (C) OncoPrint in the cbiportal was used to illustrate the distribution characteristics of samples with different genetic alterations of WDR34. A total of 66/1,093 (6\%) sequenced patients with invasive breast carcinoma exhibited alterations of WDR34. WDR34, WD domain repeat 34.

\section{Discussion}

Breast cancer is the most commonly diagnosed malignancy among females, and is a heterogeneous disease with distinct molecular subtypes (20). Several molecular subtypes of breast cancer have been identified, including luminal A, luminal B, HER2-positive and basal-like subtypes (21-23). The development of breast cancer resistance to chemoradiotherapy or targeted therapy, as well as distant metastasis, remains a challenge. Therefore, there is a requirement for the identification of potential target genes or proteins that may be beneficial for the treatment of breast cancer $(24,25)$.

The WDR protein family is involved in a variety of cellular processes, including cell cycle progression, signal transduction, apoptosis and gene regulation (7). Receptor for activated $\mathrm{C}$ kinase 1 , a member of the WDR protein family, was significantly upregulated in breast cancer, non-small-cell lung cancer, pulmonary adenocarcinoma, glioma and esophageal squamous-cell carcinoma (26). Based on Oncomine database analysis, the current study demonstrated, to the best of our knowledge for the first time, that high WDR34 mRNA expression occurred in breast cancer tissues and breast cancer cell lines. Furthermore, co-expression analysis, as evidenced by bc-GenExMiner, indicated that high WDR34 expression was positively associated with the expression levels of FOXM1 and PTTG1 (27). Previous studies indicated that FOXM1 is overexpressed in breast cancer and is strongly associated with resistance to targeted therapies and chemotherapy (28). Elevated expression of FOXM1 has been reported in a variety of human tumors, including those of the breast (29). The mean expression level of FOXM1 was previously reported to be the highest in the TNBC subtype, which was associated with poor prognosis and reduced survival time in patients with breast cancer $(29,30)$. Notably, PTTG1 is an oncogene that is important for the progression of mitosis in the metaphase-anaphase transition (31,32). Additionally, PTTG1 overexpression is associated with malignancy, particularly thyroid, breast and colorectal carcinoma (32). A previous study indicated that PTTG1 is highly expressed in patients with breast cancer and that the expression levels were correlated with the degree of malignancy in breast cancer cell lines. Furthermore, the study demonstrated that PTTG1 enhanced the migratory and invasive properties of breast cancer cells by inducing epithelial-to-mesenchymal transition (33).

Survival analysis of WDR34 expression levels in the current study demonstrated that high WDR34 expression was associated with poor OS in patients with breast cancer, particularly in the luminal B, lymph node status-positive and ER-negative subgroups, when compared with controls. These results suggested that WDR34 serves an important role in the tumor progression of hormone-sensitive breast cancer. In addition, it was revealed that high WDR34 expression frequently predicted shorter RFS in patients with breast cancer, particularly in ER-positive, HER2-negative and PR-positive subgroups. The aforementioned results suggested that patients with breast cancer with high WDR34 expression had an increased risk of mortality. Previous studies indicated that the WDR protein coronin-3, which contains five WD motifs, is associated with various invasive tumors, including melanoma, human diffuse glioma, liver cancer, breast cancer and gastric cancer (34-36). Furthermore, high expression of coronin-3 was associated with increased tumor malignancy and a more advanced clinical stage. F-box and WD repeat domain containing 7 (FBXW7) recognizes and binds to substrates via eight WD motifs at the C-terminus (37,38). However, knockout of FBXW7 with short hairpin RNA increases the KLF5 gene and Fbw7 targets the KLF5 protein for ubiquitin-mediated proteasomal degradation 
and suppresses breast cancer cell proliferation (39). Taken together, these results suggested that overexpression of WDR34 may be used as a biomarker of poor prognosis in patients with breast cancer in the future.

Previous studies have reported that HER2-positive breast cancer is frequently more aggressive and is associated with an increased risk of disease recurrence and mortality compared with other breast cancer subtypes $(23,40,41)$. At present, a substantial number of HER2-targeting agents have been introduced for the clinical treatment of breast cancer (42). One of these agents, trastuzumab (Herceptin), has several shortcomings, including its high cost and side effects such as cardiotoxicity (43). The present study indicated that the WDR34 mRNA expression level was higher in patients with HER2-positive breast cancer compared with patients with HER2-negative breast cancer. Furthermore, the WDR34 mRNA expression level was higher in patients with HER2-positive breast cancer compared with patients with the luminal A and luminal B subtypes. Thus, it may be inferred that increased levels of WDR34 mRNA may result in more aggressive breast cancer. However, it remains unknown whether the upregulation of WDR34 may be used as a target for novel agents for the treatment of HER2-positive breast cancer.

The NPI is widely used to predict survival in patients with breast cancer, and a higher NPI is associated with a worse prognosis $(44,45)$. The present study indicated that a higher NPI level was significantly associated with the expression level of WDR34 mRNA. In other words, WDR34 mRNA upregulation predicted a poorer prognosis in patients with breast cancer. In addition, high WDR34 mRNA expression was associated with a higher SBR grade, which typically suggests growing and spreading tumors (46).

Previous studies have reported that mutations of WDR34 mRNA are primarily associated with short-rib polydactyly syndrome type III and severe asphyxiating thoracic dysplasia $(8,9)$. Loss-of-function mutations of FBXW7, another WDR protein, have been identified in colorectal cancer (18\%), uterine endometrial carcinoma (15\%) and uterine carcinosarcoma (40\%), suggesting that the interactions between FBXW7 and its substrates are interrupted by disrupting the structural integrity of the WDR domain $(47,48)$. Notably, compounds targeting the WDR domain of FBXW7 are expected to antagonize binding of cyclin $\mathrm{E}$ and phenocopy the oncogenic effect of mutations that are recurrent in cancer (47). Although gene alterations of WDR34 occurred in $\sim 6 \%$ of sequenced patients with invasive breast carcinoma, no influence on OS or DFS was observed in the present study. Thus, it can be inferred that a WDR34 mRNA mutation did not significantly influence the prognosis of breast cancer. However, future studies on the correlation between WDR34 mRNA mutation and breast cancer are required.

The present study had a number of limitations. Firstly, the study only analyzed the high expression of WDR34 in patients with breast cancer compared with normal samples using comprehensive bioinformatics analysis. Functional verification was not carried out through cohort research and molecular mechanism research. Secondly, the Oncomine database is a cancer microarray data-mining platform, which can be used to identify new prognostic biomarkers. However, gene chip technology has a certain degree of false-positive results that are likely to influence the accuracy of the current study. Thirdly, the number of samples in the OS analysis using the Kaplan-Meier plotter was small, which possibly influenced the outcome. Finally, since the survival analysis was based on an online database (the Kaplan-Meier Plotter), integrated data could not be acquired to perform multivariate analysis.

In conclusion, to the best of our knowledge, this study demonstrated for the first time that the WDR34 mRNA expression was significantly increased in breast cancer tissues compared with normal tissues. Furthermore, high WDR34 mRNA expression was associated with poor OS and shorter RFS in patients with breast cancer, and may be an attractive prognostic prediction biomarker and promising therapeutic target for breast cancer. However, the role of WDR34 mRNA expression in the genesis and progression of breast cancer requires further basic and clinical study.

\section{Acknowledgements}

The authors would like to thank Professor LiZhang for providing careful guidance in writing this paper. The authors would also like to thank Wen-Jie Shi for helping with dataset usage.

\section{Funding}

This study was supported by the Chongming Committee of Science and Technology (Shanghai, China; grant no. CKY2018-11).

\section{Availability of data and materials}

The datasets used during the present study may be obtained from the corresponding author upon reasonable request.

\section{Authors' contributions}

LZ and DJH designed the experiment, provided financial support, revised the manuscript and gave final approval of the version to be published. DJH and WJS performed the statistical analysis and wrote the paper. MY collected data and revised the manuscript.

\section{Ethics approval and consent to participate}

Not applicable.

\section{Patient consent for publication}

Not applicable.

\section{Competing interests}

The authors declare that they have no competing interests.

\section{References}

1. Siegel RL, Miller KD and Jemal A: Cancer statistics, 2018. CA Cancer J Clin 68: 7-30, 2018. 
2. Kadalayil L, Khan S, Nevanlinna H, Fasching PA, Couch FJ, Hopper JL, Liu J, Maishman T, Durcan L, Gerty S, et al: Germline variation in ADAMTSL1 is associated with prognosis following breast cancer treatment in young women. Nat Commun 8: 1632, 2017.

3. Si W, Shen J, Du C, Chen D, Gu X, Li C, Yao M, Pan J, Cheng J, Jiang D, et al: A miR-20a/MAPK1/c-Myc regulatory feedback loop regulates breast carcinogenesis and chemoresistance. Cell Death Differ 25: 406-420, 2018.

4. Nicolini A, Ferrari P and Duffy MJ: Prognostic and predictive biomarkers in breast cancer: Past, present and future. Semin Cancer Biol 52: 56-73, 2018.

5. Smith TF: Diversity of WD-repeat proteins. Subcell Biochem 48: 20-30, 2008.

6. van Nocker S and Ludwig P: The WD-repeat protein superfamily in Arabidopsis: Conservation and divergence in structure and function. BMC Genomics 4: 50, 2003.

7. Gao D, Wang R, Li B, Yang Y, Zhai Z and Chen DY: WDR34 is a novel TAK1-associated suppressor of the IL-1R/TLR3/TLR4-induced NF-kappaB activation pathway. Cell Mol Life Sci 66: 2573-2584, 2009.

8. Huber C, Wu S, Kim AS, Sigaudy S, Sarukhanov A, Serre V, Baujat G, Le Quan Sang KH, Rimoin DL, Cohn DH, et al: WDR34 mutations that cause short-rib polydactyly syndrome type III/severe asphyxiating thoracic dysplasia reveal a role for the NF-кB pathway in cilia. Am J Hum Genet 93: 926-931, 2013.

9. You SH, Lee YS, Lee CP, Lin CP, Lin CY, Tsai CL, Chang YL, Cheng PJ, Wang TH and Chang SD: Identification of a c.544C $>$ T mutation in WDR34 as a deleterious recessive allele of short rib-polydactyly syndrome. Taiwan J Obstet Gynecol 56: 857-862, 2017.

10. Wu C, Li J, Peterson A, Tao K and Wang B: Loss of dynein-2 intermediate chain Wdr34 results in defects in retrograde ciliary protein trafficking and Hedgehog signaling in the mouse. Hum Mol Genet 26: 2386-2397, 2017.

11. Yamamoto JI, Kasamatsu A, Okubo Y, Nakashima D, Fushimi K, Minakawa Y, Kasama H, Shiiba M, Tanzawa H and Uzawa K: Evaluation of tryptophan-aspartic acid repeat-containing protein 34 as a novel tumor-suppressor molecule in human oral cancer. Biochem Biophys Res Commun 495: 2469-2474, 2018.

12. Mares J, Szakacsova M, Soukup V, Duskova J, Horinek A and Babjuk M: Prediction of recurrence in low and intermediate risk non-muscle invasive bladder cancer by real-time quantitative PCR analysis: cDNA microarray results. Neoplasma 60: 295-301, 2013.

13. Jiang Y, Zhang L, Kong F, Zhang M, Lv H, Liu G, Liao M, Feng R, Li J and Zhang R: MCPerm: A Monte Carlo permutation method for accurately correcting the multiple testing in a meta-analysis of genetic association studies. PLoS One 9: e89212, 2014

14. Jézéquel P, Campone M, Gouraud W, Guérin-Charbonnel C, Leux C, Ricolleau G and Campion L: bc-GenExMiner: An easy-to-use online platform for gene prognostic analyses in breast cancer. Breast Cancer Res Treat 131: 765-775, 2012.

15. Jézéquel P, Frénel JS, Campion L, Guérin-Charbonnel C, Gouraud W, Ricolleau G and Campone M: bc-GenExMiner 3.0 New mining module computes breast cancer gene expression correlation analyses. Database (Oxford) 2013: bas060, 2013.

16. Lánczky A, Nagy Á, Bottai G, Munkácsy G, Szabó A, Santarpia L and Györffy B: miRpower: A web-tool to validate survival-associated miRNAs utilizing expression data from 2178 breast cancer patients. Breast Cancer Res Treat 160: 439-446, 2016.

17. Gao J, Aksoy BA, Dogrusoz U, Dresdner G, Gross B, Sumer SO, Sun Y, Jacobsen A, Sinha R, Larsson E, et al: Integrative analysis of complex cancer genomics and clinical profiles using the cBioPortal. Sci Signal 6: pl1, 2013

18. Cerami E, Gao J, Dogrusoz U, Gross BE, Sumer SO, Aksoy BA, Jacobsen A, Byrne CJ, Heuer ML, Larsson E, et al: The cBio cancer genomics portal: An open platform for exploring multidimensional cancer genomics data. Cancer Discov 2: 401-404, 2012.

19. Curtis C, Shah SP, Chin SF, Turashvili G, Rueda OM, Dunning MJ, Speed D, Lynch AG, Samarajiwa S, Yuan Y, et al: The genomic and transcriptomic architecture of 2,000 breast tumours reveals novel subgroups. Nature 486: 346-352, 2012.

20. Goda AA, Siddique AB, Mohyeldin M, Ayoub NM and El Sayed KA: The maxi-K (BK) channel antagonist penitrem a as a novel breast cancer-targeted therapeutic. Mar Drugs 16: pii: E157, 2018

21. Goldhirsch A, Glick JH, Gelber RD, Coates AS, Thurlimann B and Senn HJ; Panel members: Meeting highlights: International expert consensus on the primary therapy of early breast cancer 2005. Ann Oncol 16: 1569-1583, 2005.
22. Sorlie T, Tibshirani R, Parker J, Hastie T, Marron JS, Nobel A, Deng S, Johnsen H, Pesich R, Geisler S, et al: Repeated observation of breast tumor subtypes in independent gene expression data sets. Proc Natl Acad Sci USA 100: 8418-8423, 2003.

23. Perou CM, Sorlie T, Eisen MB, van de Rijn M, Jeffrey SS, Rees CA, Pollack JR, Ross DT, Johnsen H, Akslen LA, et al: Molecular portraits of human breast tumours. Nature 406: 747-752, 2000.

24. Wang C, Sun X, Wang K, Wang Y, Yang F and Wang H: Breast cancer targeted chemotherapy based on doxorubicin-loaded bombesin peptide modified nanocarriers. Drug Deliv 23: 2697-2702, 2016.

25. Mahaddalkar T and Lopus M: From natural products to designer drugs: Development and molecular mechanisms action of novel anti-microtubule breast cancer therapeutics. Curr Top Med Chem 17: 2559-2568, 2017.

26. Li JJ and Xie D: RACK1, a versatile hub in cancer. Oncogene 34: 1890-1898, 2015

27. Giuliano AE, Connolly JL, Edge SB, Mittendorf EA, Rugo HS Solin LJ, Weaver DL, Winchester DJ and Hortobagyi GN: Breast Cancer-Major changes in the American Joint Committee on Cancer eighth edition cancer staging manual. CA Cancer J Clin 67: 290-303, 2017.

28. O'Regan RM and Nahta R: Targeting forkhead box M1 transcription factor in breast cancer. Biochem Pharmacol 154: 407-413, 2018.

29. Song X, Fiati Kenston SS, Zhao J, Yang D and Gu Y: Roles of FoxM1 in cell regulation and breast cancer targeting therapy. Med Oncol 34: 41, 2017.

30. Lee JJ, Lee HJ, Son BH, Kim SB, Ahn JH, Ahn SD, Cho EY and Gong G: Expression of FOXM1 and related proteins in breast cancer molecular subtypes. Int J Exp Pathol 97: 170-177, 2016.

31. Nakachi I, Helfrich BA, Spillman MA, Mickler EA, Olson CJ, Rice JL, Coldren CD, Heasley LE, Geraci MW and Stearman RS: PTTG1 levels are predictive of saracatinib sensitivity in ovarian cancer cell lines. Clin Transl Sci 9: 293-301, 2016.

32. Repo H, Gurvits N, Löyttyniemi E, Nykänen M, Lintunen M, Karra H, Kurki S, Kuopio T, Talvinen K, Söderström M and Kronqvist P: PTTG1-interacting protein (PTTG1IP/PBF) predicts breast cancer survival. BMC Cancer 17: 705, 2017.

33. Yoon CH, Kim MJ, Lee H, Kim RK, Lim EJ, Yoo KC, Lee GH, Cui YH, Oh YS, Gye MC, et al: PTTG1 oncogene promotes tumor malignancy via epithelial to mesenchymal transition and expansion of cancer stem cell population. J Biol Chem 287: 19516-19527, 2012.

34. Ren G, Tian Q, An Y, Feng B, Lu Y, Liang J, Li K, Shang Y, Nie $Y$, Wang $X$ and Fan D: Coronin 3 promotes gastric cancer metastasis via the up-regulation of MMP-9 and cathepsin K. Mol Cancer 11: 67, 2012.

35. Iizaka M, Han HJ, Akashi H, Furukawa Y, Nakajima Y, Sugano S, Ogawa M and Nakamura Y: Isolation and chromosomal assignment of a novel human gene, $\mathrm{CORO1C}$, homologous to coronin-like actin-binding proteins. Cytogenet Cell Genet 88: 221-224, 2000.

36. Thal D, Xavier CP, Rosentreter A, Linder S, Friedrichs B, Waha A, Pietsch T, Stumpf M, Noegel A and Clemen C: Expression of coronin-3 (coronin-1C) in diffuse gliomas is related to malignancy. J Pathol 214: 415-424, 2008.

37. Li M, Ouyang L, Zheng Z, Xiang D, Ti A, Li L, Dan Y, Yu C and $\mathrm{Li}$ W: E3 ubiquitin ligase FBW7 $\alpha$ inhibits cholangiocarcinoma cell proliferation by downregulating $\mathrm{c}-\mathrm{Myc}$ and cyclin E. Oncol Rep 37: 1627-1636, 2017.

38. Wang J, Wang H, Peters M, Ding N, Ribback S, Utpatel K, Cigliano A, Dombrowski F, Xu M, Chen X, et al: Loss of Fbxw7 synergizes with activated AKT signaling to promote c-Myc dependent cholangiocarcinogenesis. J Hepatol pii: S0168-8278: 30342-30343, 2019.

39. Zhao D, Zheng HQ, Zhou Z and Chen C: The Fbw7 tumor suppressor targets KLF5 for ubiquitin-mediated degradation and suppresses breast cell proliferation. Cancer Res 70: 4728-4738, 2010.

40. Krishnamurti U and Silverman JF: HER2 in breast cancer: A review and update. Adv Anat Pathol 21: 100-107, 2014.

41. Zhang K, Hong R, Kaping L, Xu F, Xia W, Qin G, Zheng Q, Lu Q, Zhai Q, Shi Y, et al: CDK4/6 inhibitor palbociclib enhances the effect of pyrotinib in HER2-positive breast cancer. Cancer Lett 447: 130-140, 2019.

42. Ahmed S, Sami A and Xiang J: HER2-directed therapy: Current treatment options for HER2-positive breast cancer. Breast Cancer 22: 101-116, 2015. 
43. Mercogliano MF, De Martino M, Venturutti L, Rivas MA, Proietti CJ, Inurrigarro G, Frahm I, Allemand DH, Deza EG, Ares S, et al: $\mathrm{TNF} \alpha$-induced mucin 4 expression elicits trastuzumab resistance in HER2-positive breast cancer. Clin Cancer Res 23: 636-648, 2017.

44. Hearne BJ, Teare MD, Butt M and Donaldson L: Comparison of Nottingham Prognostic Index and Adjuvant Online prognostic tools in young women with breast cancer: Review of a single-institution experience. BMJ Open 5: e005576, 2015.

45. Albergaria A, Ricardo S, Milanezi F, Carneiro V, Amendoeira I, Vieira D, Cameselle-Teijeiro J and Schmitt F: Nottingham Prognostic Index in triple-negative breast cancer: A reliable prognostic tool? BMC Cancer 11: 299, 2011.

46. Kabbage M, Trimeche M, Ben Nasr H, Hammann P, Kuhn L, Hamrita B and Chahed K: Tropomyosin- 4 correlates with higher SBR grades and tubular differentiation in infiltrating ductal breast carcinomas: An immunohistochemical and proteomics-based study. Tumour Biol 34: 3593-3602, 2013.
47. Song R, Wang ZD and Schapira M: Disease association and druggability of WD40 repeat proteins. J Proteome Res 16: 3766-3773, 2017

48. Yuan Y, Qi G, Shen H, Guo A, Cao F, Zhu Y, Xiao C, Chang W and Zheng S: Clinical significance and biological function of WD repeat domain 54 as an oncogene in colorectal cancer. Int J Cancer 144: 1584-1595, 2019.

(c) (i) () This work is licensed under a Creative Commons Attribution-NonCommercial-NoDerivatives 4.0 International (CC BY-NC-ND 4.0) License. 